\title{
Experimental Invesitigation and Modeling of Rainfall Runoff Process
}

\author{
Ankit Chakravarti ${ }^{1 *}$ and M.K. Jain² \\ 'Department of Civil Engineering, Indian Institute of Technology Roorkee, Roorkee-247667, \\ India; ankitchakravarti@gmail.com \\ 2Department of Hydrology, Indian Institute of Technology Roorkee, Roorkee-247667, India; jain.mkj@gmail.com
}

\begin{abstract}
Rainfall-runoff process of a watershed is important for water resources planning, flood forecasting, design flood estimation, movement of pollutants transport through rainfall runoff process, and many other applications. For a mathematical simulation of this phenomenon, controlled set of experiments were conducted to investigate this process through experimentation on the catchment system placed over a rainfall simulator to obtain runoff hydrograph data. The experiments were carried out over a non-cohesive sediment layer having sediment size of $0.5 \mathrm{~mm}$ to $1 \mathrm{~mm}$ placed over an impermeable plane surface (smooth metal sheet), with a uniform rectangular cross section of dimension one meter wide and two meter long. Total 12 laboratory experiments were conducted to know behavior of this phenomenon using rainfall simulator. The generated experimental data were simulated using a one-dimensional finite difference numerical model of kinematic wave equation for overland flow to investigate the effects of variation in rainfall intensity and surface slope on the overland hydrograph. The data was collected for catchment slope between $1 \%$ to $4 \%$ and rainfall intensity varies from 30 to $90 \mathrm{~mm} / \mathrm{hr}$. The comparison of observed and simulated runoff hydrograph reveals that the kinematic wave model simulates the rising, equilibrium discharge and upper part of recession limb reasonably well in observed hydrograph with Nash-Sutcliffe efficiency greater than $95 \%$. However, in all the experiments, the lower portion of recession limb of the observed hydrographs remained under predicted because of prolonged flow of water. The reason behind this variation may be attributed to the retention of runoff of the recession limb because of surface water tension prevailing over the overland flow bed, channel bed and even over the weir model used for flow measurement. The study further reveals that the resistance due to flow decrease linearly with increase in catchment slope for a given rainfall intensity. It was also found that for a given rainfall intensity, an increase in the catchment slope reduces the time to peak.
\end{abstract}

Keywords: Kinematic Wave, Laboratory Experiment, Rainfall-Runoff Modelling, Surface Roughness Simulation

\section{Introduction}

Rainfall- runoff processes plays an important role in hydrological cycle. The movement of water has mainly arisen from the need to evaluate the amount of available runoff water at a particular location to meet local demand as well as risk of flooding due to excess water. Rainfallrunoff estimation from a watershed is important for safe and economical design of hydrological projects for the purpose of water resources planning, watershed management, water resources economics, flood forecasting etc. The hydraulics of surface runoff are very important in determining flow depths and velocities and, hence, the capacity of the flow to entrain and transport sediment and chemicals (Tayfur et al. 1993). Overland flow can be defined as a thin sheet of flow occurring before irregularities cause a gathering of the runoff into discrete stream channels (Motha and Wigham 1995). It is generated as a result of rainfall in excess of the saturated hydraulic conductivity of the soil or by saturation of the soil surfaces Woolhiser ${ }^{14}$.

A number of models such as physically based and conceptual models have been used to simulate the rainfall runoff process. However, due to its complexity and

${ }^{*}$ Author for correspondence 
spatio-temporal variation, few models can accurately simulate this highly non-linear process. There are number of climatic and physiographic factors that significantly affect the transformation of rainfall into runoff in a catchment. The rain falling on the catchment undergoes number of transformations under the influence of these factors before it emerges as runoff at the catchment outlet.

Rainfall simulation has become a very effective technique for modeling overland flows, soil erosion and rainfall runoff ${ }^{1,3,16,17}$. Rainfall simulation makes it possible to control the spatial and temporal characteristics of precipitation. It employs a watershed experimentation system as a tool for research of the behavior of the system under varying conditions. The benefits of using the rainfall simulation approach are well documented, with versatility being the foremost advantage ${ }^{16}$ (Meyer 1965). It gives ability to repeat experiments for predefined set of conditions. In addition, developing numerical models that can predict accurately surface runoff is of interest to a wide variety of users, including city planners and irrigation practitioners. These models can also be easily extended to predict the fate and transport of contaminants along the surface. It is widely accepted that a significant amount of contaminants originates from nonpoint sources and is carried across the landscape by overland flow.

\section{Review of Literature}

For the study of rainfall runoff process, the factor that affects topographic and hydrological factors for runoff generation has been investigated by number of investigators on international literature in the past but still continue to be the object of research ${ }^{1}$ (e.g., Dunne, 1978; Meyer, 1981; de Lima, 1988; Auzet et al., 1995; Basic et al., 2001; Larue, 2001; Huang et al., 2002). However, runoff, infiltration and soil erosion have been extensively studied in the field and laboratory most of the studies using simulated rainfall have applied rainfall at a constant rate. This contrasts with natural rainfall, which is highly variable in both time and space ${ }^{20}$ (e.g., Huff, 1967; Eagleson, 1978; Sharon, 1980; de Lima, 1998).

Willems ${ }^{20}$ studied that the rainfall simulation provides control of the spatial and temporal characteristics of precipitation, at both field and laboratory scale. Smith and Woolhiser ${ }^{14}$ used a kinematic wave approximation to model the unsteady overland flow and were linked dynamically to an infiltration model by using bound- ary conditions at soil surface. The model was tested by comparisons to data from laboratory experiment and a field plot. The study found good agreement between measured and predicted hydrographs, but differences in the recession limb were noted. The influence of slope was not examined in this study. de Lima ${ }^{4}$ conducted laboratory experiments to emphasize the importance of spatial rainfall intensity patterns of moving rainstorms on overland flow. A simple numerical model, based on the non-linear kinematic wave, was used for comparing the results for hypothetical storms moving up and down an impervious plane surface. de Lima $^{5}$ conducted laboratory experiments on an impermeable smooth plane surface with a movable sprinkling-type rainfall simulator to simulate a moving storm. The results indicate considerable differences in runoff volumes and peaks and in overland flow hydrograph shapes, for storms moving upstream and downstream at differing velocities. Bronstert and Bardossy (2003) reported a case study using data from an experimental hill slope in a loess catchment.

Flood wave propagation in overland flow may be described by the complete equations of motion for unsteady non uniform flow, known as the dynamic wave equations, first proposed by St. Venant in 1871. These equations are highly nonlinear and therefore do not have analytical solutions. Under a different set of simplifying assumptions, more practical kinematic-wave is presented $^{18}$. These models constitute a relatively accurate physical representation of the flow ${ }^{19}$, both approaches allow distributed overland flow and channel flow routing. Kinematic wave model substitutes a steady uniform flow (stage-discharge) relationship for the momentum equation. However, unsteady flow is preserved through the continuity equation.

Henderson ${ }^{6}$ noted that kinematic waves behave closely to observed natural flood waves in steep rivers (slopes $>$ 0.002). The overland flow component of the hydrological cycle is probably the most suited to such representation. For overland flow, the kinematic wave approximation to the Sant Venant equations of unsteady gradually-varied free surface flow is considered appropriate to most practical occurrences. The technique has been widely applied in practice, and has been investigate in a number of experimental studies.

Lighthill $^{10}$ developed the kinematic wave theory. The theory became an accepted tool for modeling not only surface runoff but also for subsurface flow, soil moisture movement, macro pore flow, snowmelt runoff, and soil 
erosion. Smith ${ }^{14}$ focused on overland flow over sloping infiltrating surfaces. The kinematic wave approximation was used to describe unsteady overland flow and was linked dynamically to an infiltration model by using boundary conditions at soil surface. Singh ${ }^{13}$ conducted comparative study of kinematic wave model and Nash model for a converging surface. The interdependent behavior of kinematic wave parameters is shown and based on this observation an experimental justification is given for retaining only one parameter in the kinematic wave model.

The experimental investigations could be performed to understand surface, sub-surface or ground water runoff generation mechanism. Runoff is generated by rainstorms and its occurrence and quantity are dependent on the characteristics of the rainfall event, i.e. intensity, duration and distribution. The mechanism of surface runoff generation is however the focus of the present investigation. The main objective of the present study was to quantify the rainfall runoff process and its theoretical validation using developed model to simulate observed and computed data. Experiments were carried out using rainfall simulator. Several bed slopes and rainfall intensity were used for carrying out the laboratory experiments.

\subsection{Laboratory Set-up}

\subsubsection{Rainfall Simulator}

The experiments described in this research work were carried out using a soil flume and a rainfall simulator. The laboratory set-up for runoff generation was carried out in the present investigation known as Advanced Hydrologic System. Figure (1) shows a photographic representation of the experimental setup. Advanced Hydrologic System enables to demonstrate some of the major physical processes found in hydrology and fluvial geomorphology, including rainfall-runoff hydrographs for catchment areas of varying permeability; the abstraction of ground water by wells, with surface recharge and without surface recharge from rainfall; the formation of river features and effects of sediment transport. Realistic results can be obtained from this small scale, floor standing apparatus, which can be conveniently located in a laboratory and requires no special services. Thus the apparatus is useful to study the part of hydrological cycle bounded by the arrival of net rainfall on ground surface and catchment runoff either by surface streams or well abstraction. The basic components of the simulator are tilting flume for slope adjustment, continuous-spray, nozzles, supporting the nozzles; and the connections to the pumping system and a constant head tank, and one electric motor for artificial rainfall over the catchment. The pumping system gives a stable pressure to avoid variations in rainfall intensity during the simulated rainfall events. Pressure gauges monitored the pressure at the pump and nozzle. Although the rainfall simulator permits the use of several rows of spray nozzles, the experiments described in this study used eight nozzles, at a fixed height.

\subsubsection{The Flume}

The impermeable plane surface (smooth painted metal sheet) had a uniform rectangular cross-section having $1.25 \mathrm{~m}$ wide and $5 \mathrm{~m}$ long, and that can be adjusted up to 0 to $5 \%$ slope. The flume is filled with sediment having particle size ranges between 0.5 to $1.0 \mathrm{~mm}$.

\subsubsection{The Runoff Recording System}

The purpose of runoff recording system is to determine the overland flow hydrographs in a particular time, the runoff generated by each rainfall event is collected in a container placed at the bottom end of the flume, for the determination of the overland flow hydrographs. The runoff recording system used a high sensitivity pressure transducer (depth sensor) connected to a data logger which records the amount of runoff water passing through a collecting tank in time and the water level in the container.

\subsubsection{Rainfall Intensity Pattern}

A recent study has emphasized the importance of spatial rainfall intensity patterns of a storm on the shape of the

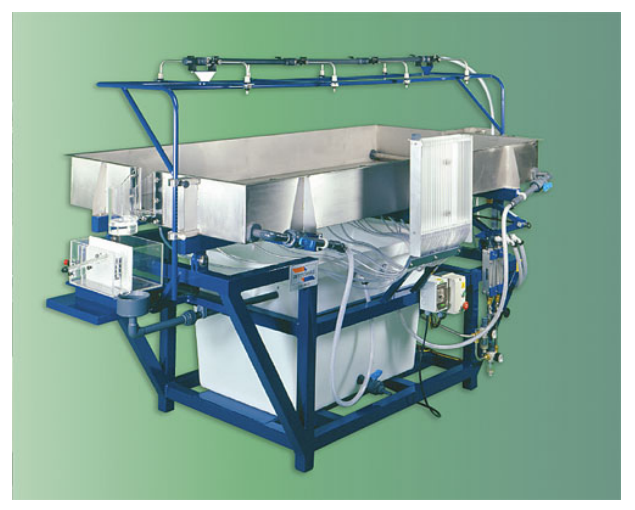

Figure 1. S-12 MKII-50 Advanced Hydrologic Systems (Rainfall Simulator). 
runoff hydrographs, times to peak and peak discharges (e.g. de Lima ${ }^{4}$ ). However, in this study, the simulated rainfall pattern is used having three different pattern of rainfall intensity i.e. $30 \mathrm{~mm} / \mathrm{hr}$. to $90 \mathrm{~mm} / \mathrm{hr}$.

\section{Methodology}

The experiments is carried out on a sand layer placed over an impermeable plane surface (smooth metal sheet), with a uniform rectangular cross section $1 \mathrm{~m}$ wide and $2 \mathrm{~m}$ long, as shown in figure 1 , the sediment particle diameter of 0.5 to $1.0 \mathrm{~mm}$ is required to fill over the flume. There is a slop adjustment device for adjusting the slope in the range from $0 \%$ to $5 \%$. Similar arrangement for rainfall flow rate with different intensity ranging from 30 $\mathrm{mm} / \mathrm{hr}$ to $90 \mathrm{~mm} / \mathrm{hr}$ is possible with the help of $1 / 2 \mathrm{HP}$ pump. Water is reaches in the pipe line which is arranged above the sand tank and through the spray nozzle artificial rainfall is spread over the catchment area having $2 \mathrm{~m}$ length and $1 \mathrm{~m}$ width in the flume filled with sand. During rainfall water flows over surface of sand and reach to the outlet and that runoff water flows through collecting tank filled with rectangular weir to measure the runoff water passing over it. The Depth sensor is attached below the collecting tank to give the height over weir.

\subsection{Mathematical Modeling}

\subsubsection{Kinematic Wave Formulation}

The Kinematic wave (KW) theory was developed by Lighthill $^{10}$, ever since then KW theory has been widely used for modeling overland and stream flow. KW formulation uses physiographic parameters such Overland roughness, slope, drainage area and length, and soil characteristics for computation of overland flow. The KW approximation of Saint-Venant's equation can be written as

$$
\begin{gathered}
\frac{\partial A}{\partial t}+\frac{\partial(v A)}{\partial x}=q_{l} \\
Q=a A^{m}
\end{gathered}
$$

Where $v$ is the flow velocity in $\mathrm{m} / \mathrm{s}, A$ is the water flow area in $\mathrm{m}^{2}, Q$ is the discharge in $\mathrm{m}^{3} / \mathrm{s}, q_{1}$ is lateral inflow rate in $\mathrm{m}^{2} / \mathrm{s}, t$ is time in second, $x$ is the distance measured positive in the direction of flow in meter, and $\alpha$ and $\mathrm{m}$ are parameters of the kinematic wave parameter which are closely related to the characteristics of the flow (Singh 1996). Equation (1) and (2) are the governing partial differential equation of the kinematic wave model which may be written in the combined form as follows:

$$
\frac{\partial A}{\partial t}+\alpha m A^{m-1} \frac{\partial A}{\partial x}=q_{l}
$$

Assuming an overland strip of unit width, the water area $A$ can be replaced with the overland flow depth $h$, and lateral flow by rainfall excess intensity (i.e. $q_{1}=r-f$ ). Thus, the resulting kinematic wave equation for overland flows is as follows:

$$
\begin{gathered}
\frac{\partial h}{\partial t}+a_{o} m_{o} h^{m_{o}-1} \frac{\partial h}{\partial x}=r-f \\
q_{o}=\alpha_{o} h^{m_{o}}
\end{gathered}
$$

Where, $r$ is the rainfall intensity in $\mathrm{m} / \mathrm{s}, f$ is the infiltration rate in $\mathrm{m} / \mathrm{s}$, and $\alpha_{o}=s_{o}^{1 / 2} / n_{o}$ and $m_{o}=5 / 3$. The most commonly used initial condition for overland flow is a dry surface. For overland flow, the initial and boundary conditions are prescribed keeping in mind the fact that the overland flow in small watersheds has negligible base flow. Considering these conditions the initial and boundary conditions have been defined as follow:

$$
\begin{aligned}
& h_{o}^{i}=0 \text { for every } x \text { at } t=0 \\
& q_{o i}^{o}=0 \text { for every } x \text { at } t=0 \\
& h_{o}^{o}=0 \text { for every } t \text { at } x=0 \\
& q_{o 0}^{j}=0 \text { for every } t \text { at } x=0
\end{aligned}
$$

The calculation is made in a Cartesian coordinate rectangular grid with the $x$-axis representing the distance in direction $i$, and having a step length $\Delta x$, and time on the $y$ axis with notation $\mathrm{j}$, and having the time step of $\Delta t$. Equation (4) and (5) can be solved using analytic method for simple configurations Chow et. al (1988), however, in present study, the governing differential equation were solved numerically using explicit numerical method. From equation (1) and (2) using implicit finite difference method

$$
\begin{gathered}
\frac{h_{i+1}^{t+1}-h_{i+1}^{t}}{\Delta t}+\frac{q_{i+1}^{t+1}-q_{i}^{t+1}}{\Delta x}=(r-f)_{i+1}^{t+1} \\
q_{i+1}^{t+1}=\alpha\left(h_{i+1}^{t+1}\right)^{m} \\
q_{i}^{t+1}=\alpha\left(h_{i}^{t+1}\right)^{m}
\end{gathered}
$$


After simplifying the these equation,

$f\left(h_{i+1}^{t+1}\right)=\frac{\Delta t}{\Delta x} a\left(h_{i+1}^{t+1}\right)^{m}-\left(\frac{\Delta t}{\Delta x} a\left(h_{i}^{t+1}\right)^{m}+h_{i+1}^{t}+\Delta t(r-f)_{i+1}^{t+1}\right)+h_{i+1}^{t+1}$

By solving the above equation using Newton-Raphson iterative method,

$$
\left(h_{i+1}^{t+1}\right)_{k+1}=\left(h_{i+1}^{t+1}\right)_{k} \frac{f\left(h_{i+1}^{t+1}\right)_{k}}{f^{\prime}\left(h_{i+1}^{t+1}\right)_{k}}
$$

Where,

$$
f^{\prime}\left(h_{i+1}^{t+1}\right)=1+\frac{\Delta t}{\Delta x} a m\left(h_{i+1}^{t+1}\right)^{m-1}
$$

\subsection{Nash Sutcliffe Criterion}

The closeness of reproduction of the benchmark solution for performance evaluation of kinematic wave model solution were evaluated using the well known Nash-Sutcliffe efficiency criterion (Nash-Sutcliffe, 1970). It is experssed as;

Nash-Sutcliffe Efficiency in (\%),

$$
N E S=\left(1 \frac{\sum_{i-1}^{n}\left(Y_{o}-Y_{c}\right)^{2}}{\sum_{i-1}^{n}\left(Y_{o}-Y_{m}\right)^{2}}\right) \times 100
$$

Where, $Y_{o}=$ Observed flow (Experimental rainfall flow) value at time $t, Y_{c}=$ Computed flow (kinemaic flow) value at time $t, Y_{m}=$ Mean of observed values.

\subsection{Error in Runoff Volume Computation}

The error in runoff volume for the present study was estimated by,

Volumetric error, in \% $=\left(1 \frac{Y_{c}}{Y_{o}}\right) \times 100$
Where, $Y_{0}=$ Runoff volume observed and $Y_{c}=$ Runoff volume computed.

\section{Analysis and Discussion of Results}

Experimental data obtained from Advanced Hydrologic system (rainfall simulator) is analysied using one dimentional kinematic wave overland flow simulation model. The one dimentional kinematic wave model for overland flow, was developed in Fortran programming language. The simulation was done using time step $\Delta t$ of $5 \mathrm{sec}$ and spatial grid size $\Delta x$ is taken as $1 \mathrm{~cm}$. Experimental data were simulated using developed model in order to study the overland flow roughness due to variation of slope and rainfall intensity on the catchment. Data was observed for catchment slope between $1 \%$ to $4 \%$ and rainfall intensity varies between 30 to $90 \mathrm{~mm} / \mathrm{hr}$.

Developed kinematic wave model was calibrated for manning's roughness coefficient " $n$ " to fit into data observed from experiment for $30 \mathrm{~mm} / \mathrm{hr}$ rainfall intensity for different slopes. Plote between observed and model computated hydrograph are shown in Figure 2 to 5 for slope of $1 \%, 2 \%, 3 \%$, and $4 \%$ respectively.

As can be seen from these plots the kinematic wave model could reproduce resonably well rising limb of the observed hydrograph as well as steady state discharge. In case of falling limb of the hydrograph, two segments are clearly visible. On where only surface runoff domainates which is reproduceed well by kinematic wave model and second the release of water from sand bed, which the kinematic wave model has not simulated because the mechanism of release of water from sand bed was not incorporated in the kinematic wave model.

\begin{tabular}{|c|c|c|c|c|c|c|c|c|}
\hline \multirow[t]{3}{*}{ S.No } & \multirow[t]{2}{*}{ Slope } & \multicolumn{3}{|c|}{ Volume } & \multicolumn{3}{|c|}{ Time to Peak } & \multirow[t]{2}{*}{ NSE } \\
\hline & & Observed & Computed & Error & Observed & Computed & Error & \\
\hline & $(\%)$ & (lit) & (lit) & $(\%)$ & $(\min )$ & $(\min )$ & $(\%)$ & $(\%)$ \\
\hline 1 & 1 & 9.3 & 7.9 & 4.3 & 2.7 & 2.4 & 11.1 & 98 \\
\hline 2 & 2 & 6.3 & 5.9 & 6.3 & 2.3 & 2.1 & 8.6 & 97.2 \\
\hline 3 & 3 & 8.3 & 7.9 & 4.8 & 2.1 & 2.0 & 4.7 & 91 \\
\hline 4 & 4 & 7.6 & 7.3 & 3.9 & 2.0 & 1.8 & 5 & 93.2 \\
\hline
\end{tabular}

Table 1. Pertinent characteristics of observed and computed hydrograph for $30 \mathrm{~mm} / \mathrm{hr}$ intensity of rainfall and Area $=2 \mathrm{~m}^{2}$ 
Table 2. Pertinent characteristics of observed and computed hydrograph for $60 \mathrm{~mm} / \mathrm{hr}$ intensity of rainfall and Area $=2 \mathrm{~m}^{2}$

\begin{tabular}{ccccccccc}
\hline \multirow{2}{*}{ S.No } & Slope & \multicolumn{3}{c}{ Volume } & \multicolumn{3}{c}{ Time to Peak } & NSE \\
\cline { 2 - 8 } & & Observed & Computed & Error & Observed & Computed & Error & \\
\cline { 2 - 9 } & $(\%)$ & $($ lit $)$ & $($ lit $)$ & $(\%)$ & $($ min $)$ & $($ min $)$ & $(\%)$ & $(\%)$ \\
\hline 1 & 1 & 12.5 & 12.2 & 2.4 & 3.9 & 3.5 & 10.2 & 97.8 \\
2 & 2 & 10.4 & 10.1 & 2.8 & 3.2 & 2.9 & 9.3 & 96.6 \\
3 & 3 & 16.2 & 15.8 & 2.4 & 2.8 & 2.6 & 7.1 & 97.0 \\
4 & 4 & 12.5 & 12.1 & 3.2 & 2.5 & 2.4 & 4 & 92.6 \\
\hline
\end{tabular}

Table 3. Pertinent characteristics of observed and computed hydrograph for $90 \mathrm{~mm} / \mathrm{hr}$ intensity of rainfall and Area $=2 \mathrm{~m}^{2}$

\begin{tabular}{ccccccccc}
\hline \multirow{2}{*}{ S.No } & \multirow{2}{*}{ Slope } & \multicolumn{5}{c}{ Volume } & \multicolumn{5}{c}{ Time to Peak } & \multirow{2}{*}{ NSE } \\
\cline { 2 - 7 } & & Observed & Computed & Error & Observed & Computed & Error & \\
\hline 1 & $(\%)$ & $($ lit $)$ & $($ lit $)$ & $(\%)$ & $(\min )$ & $(\min )$ & $(\%)$ & $(\%)$ \\
\hline 2 & 1 & 16.1 & 15.7 & 2.4 & 3.6 & 3.3 & 8.3 & 96 \\
3 & 2 & 18.3 & 17.9 & 2.1 & 3.1 & 2.9 & 6.4 & 97 \\
4 & 3 & 15.4 & 14.9 & 3.2 & 3.2 & 3 & 6.2 & 96.1 \\
& 4 & 15.1 & 14.7 & 2.6 & 2.6 & 2.5 & 3.8 & 96.7 \\
\hline
\end{tabular}

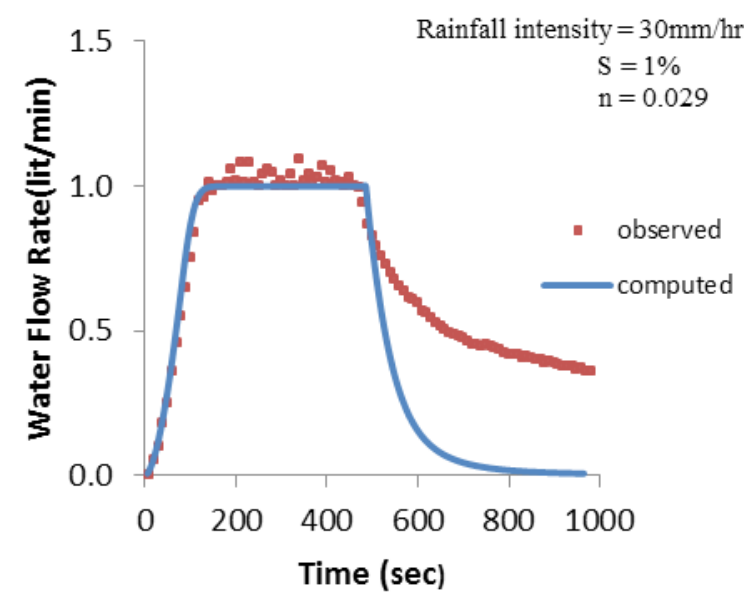

Figure 2. Comparison of observed and computed hydrograph for rain fall intensity $30 \mathrm{~mm} / \mathrm{hr}$ at $1 \%$ slope.

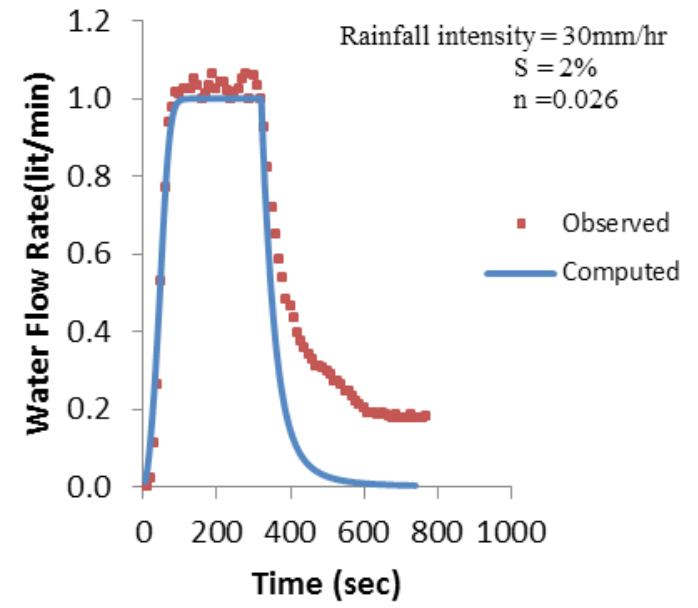

Figure 3. Comparison of observed and computed hydrograph for rain fall intensity $30 \mathrm{~mm} / \mathrm{hr}$ at $2 \%$ slope. 


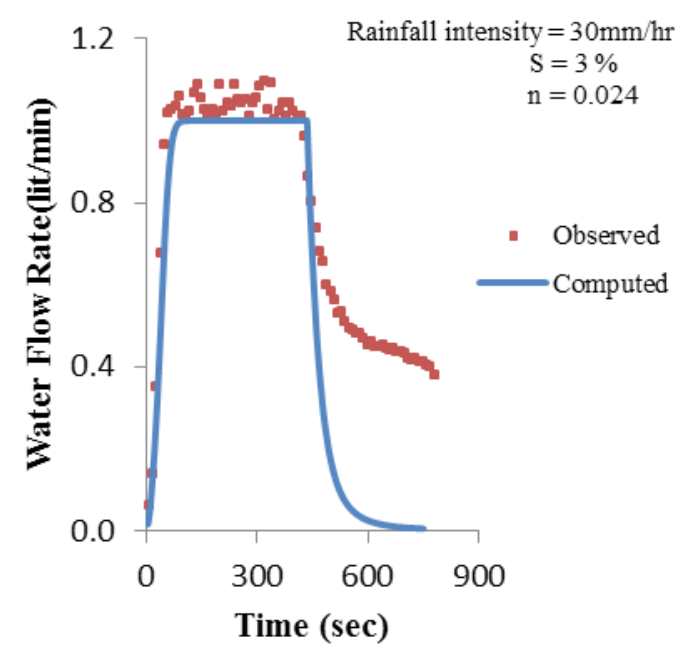

Figure 4. Comparison of observed and computed hydrograph for rainfall intensity $30 \mathrm{~mm} / \mathrm{hr}$ at $3 \%$ slope of the plane.

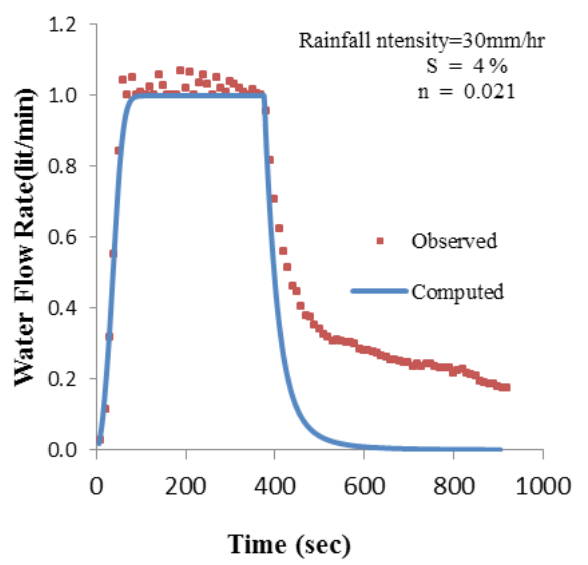

Figure 5. Comparison of observed and computed hydrograph for rainfall intensity $30 \mathrm{~mm} / \mathrm{hr}$ at $4 \%$ slope of the plane.

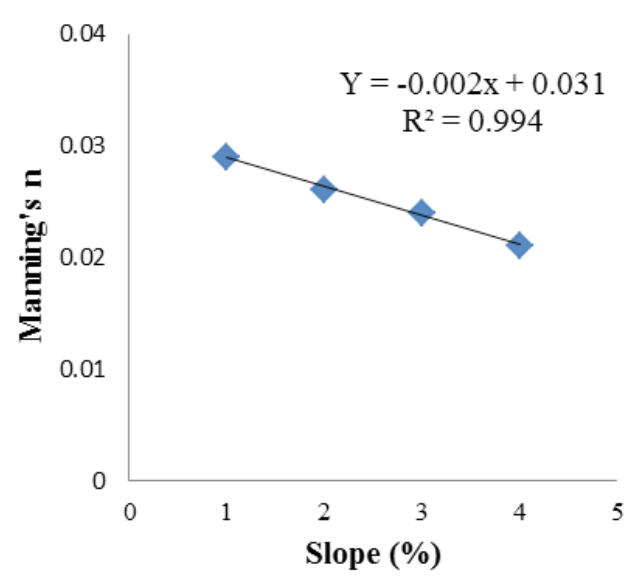

Figure 6. Variation of Manning's roughness with overland flow plane slope for rainfall intensity $30 \mathrm{~mm} / \mathrm{hr}$.

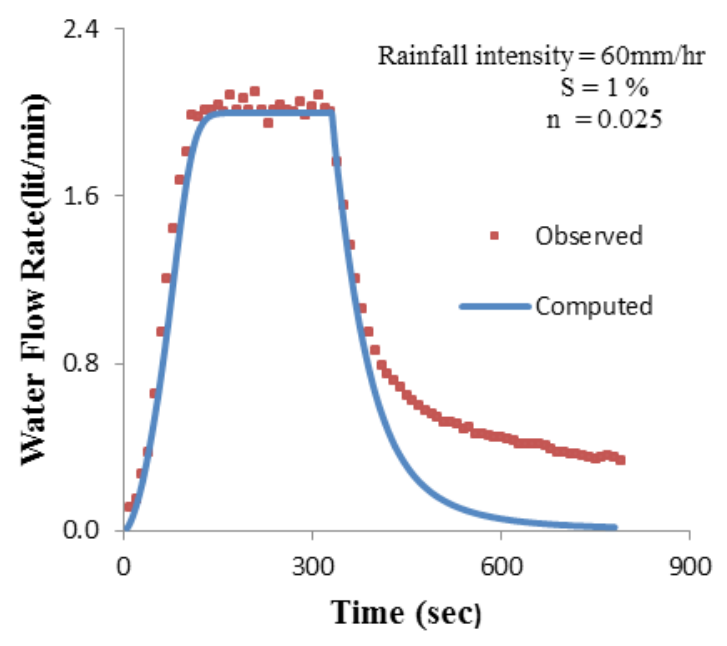

Figure 7. Comparison of observed and computed hydrograph for rainfall intensity $60 \mathrm{~mm} / \mathrm{hr}$ at $1 \%$ slope of the plane.

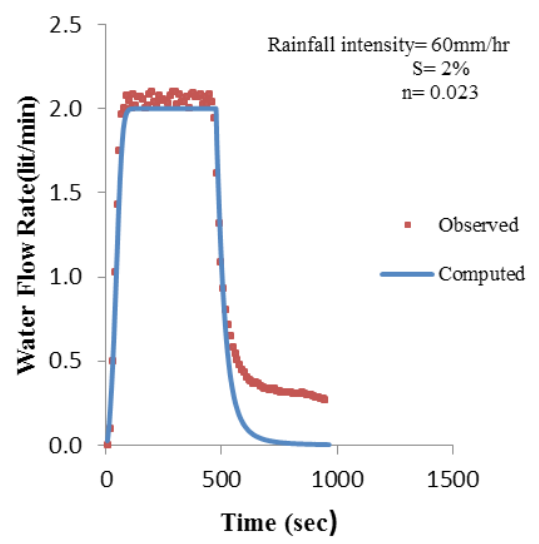

Figure 8. Comparison of observed and computed hydrograph for rainfall intensity $60 \mathrm{~mm} / \mathrm{hr}$ at $2 \%$ slope of the plane.

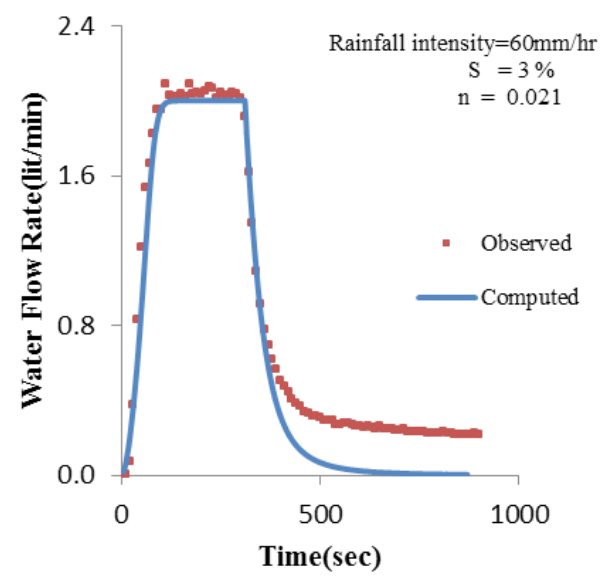

Figure 9. Comparison of observed and computed hydrograph for rainfall intensity $60 \mathrm{~mm} / \mathrm{hr}$ at $3 \%$ slope of the plane. 


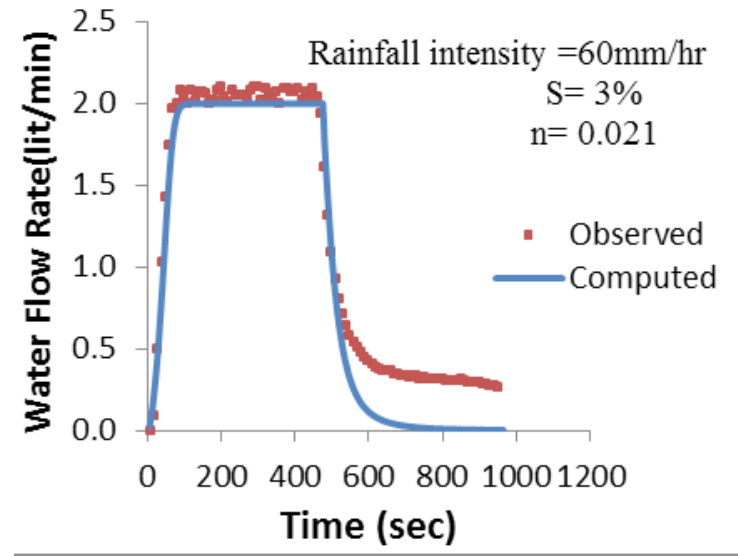

Figure 10. Comparison of observed and computed hydrograph for rain fall intensity at $4 \%$ slope of the plane.

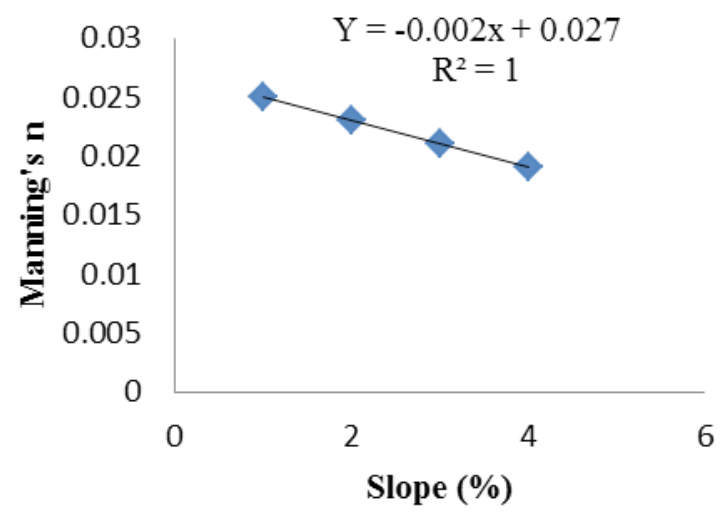

Figure 11. Variation of Manning's roughness with overland flow plane slope for rainfall intensity $60 \mathrm{~mm} / \mathrm{hr}$.

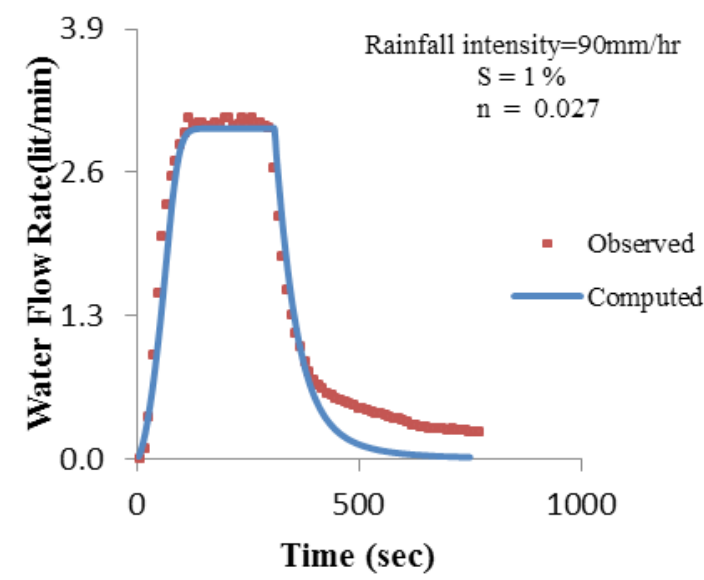

Figure 12. Comparison of observed and computed hydrograph for rainfall intensity $90 \mathrm{~mm} / \mathrm{hr}$ at $1 \%$ slope of the plane.

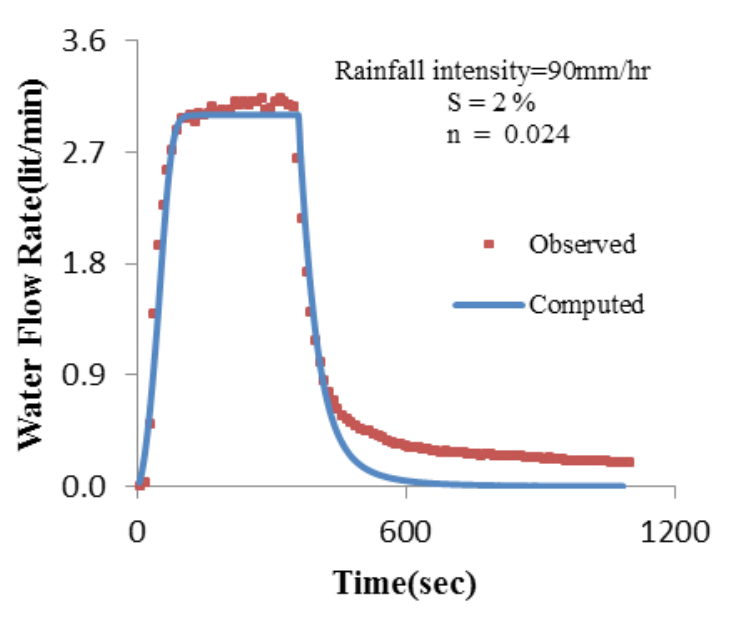

Figure 13. Comparison of observed and computed hydrograph for rainfall intensity $90 \mathrm{~mm} / \mathrm{hr}$ at $2 \%$ slope of the plane.

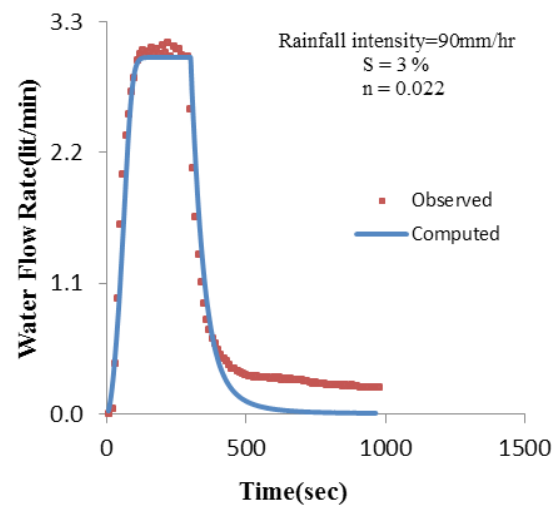

Figure 14. Comparison of observed and computed hydrograph for rainfall intensity $90 \mathrm{~mm} / \mathrm{hr}$ at $3 \%$ slope of the plane.

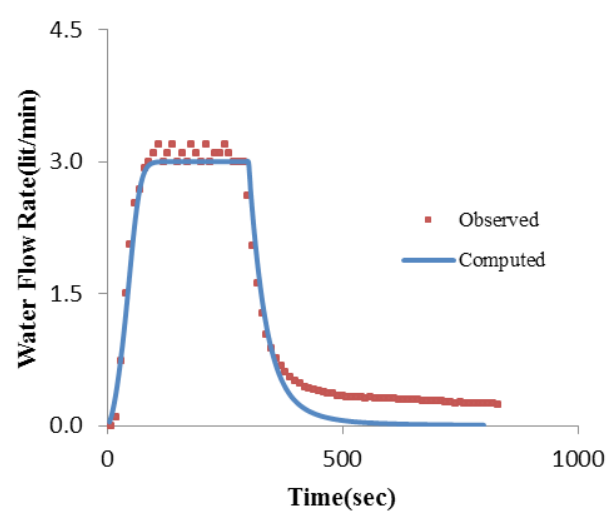

Figure 15. Comparison of observed and computed hydrograph for rainfall intensity $90 \mathrm{~mm} / \mathrm{hr}$ at $4 \%$ slope of the plane. 


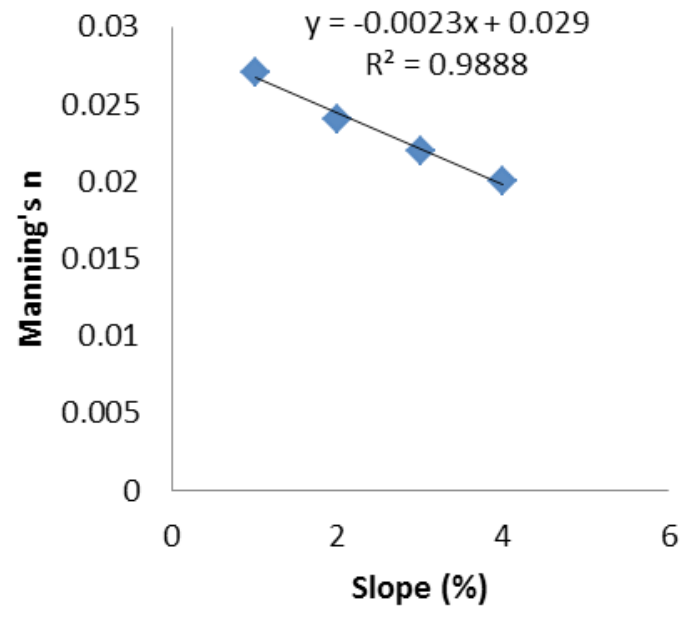

Figure 16. Variation of Manning's roughness with overland flow plane slope for rainfall intensity $90 \mathrm{~mm} / \mathrm{hr}$.

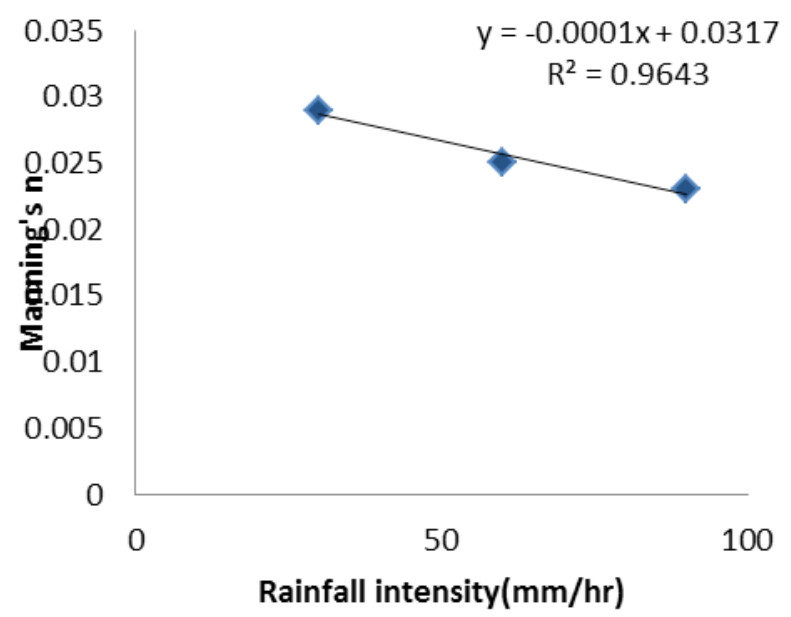

Figure 17. Variation of Manning's roughness with rainfall intensity for $1 \%$ slope of the plane.

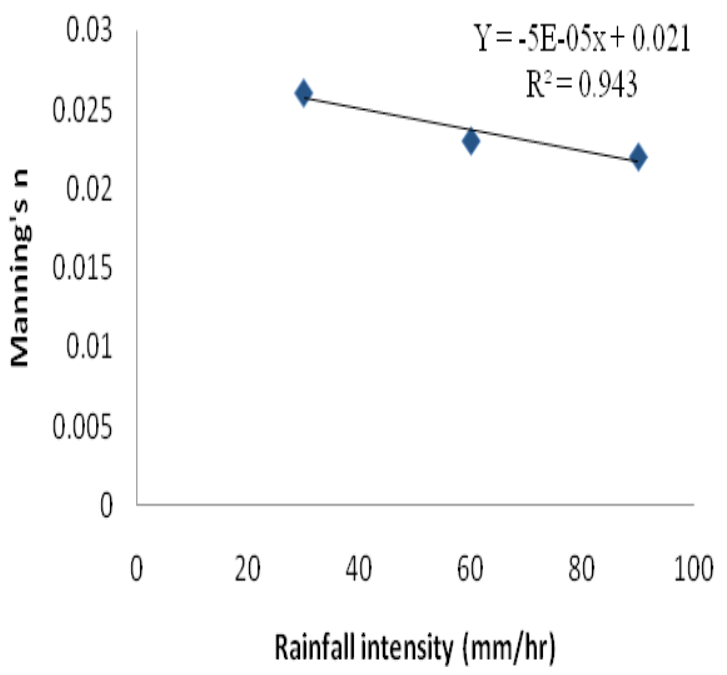

Figure 19. Variation of Manning's roughness with rainfall intensity for $3 \%$ slope of the plane.

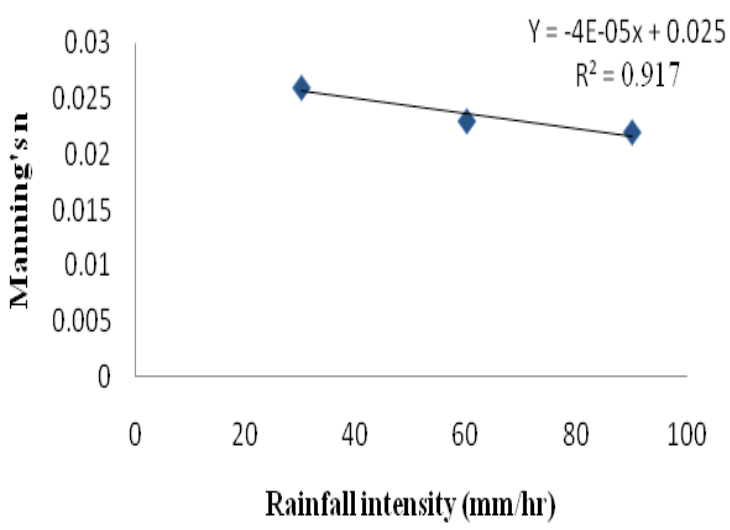

Figure 20. Variation of Manning's roughness with rainfall intensity for $4 \%$ slope of the plane.

$y=-7 E-05 x+0.0277$

$\mathrm{R}^{2}=0.9231$

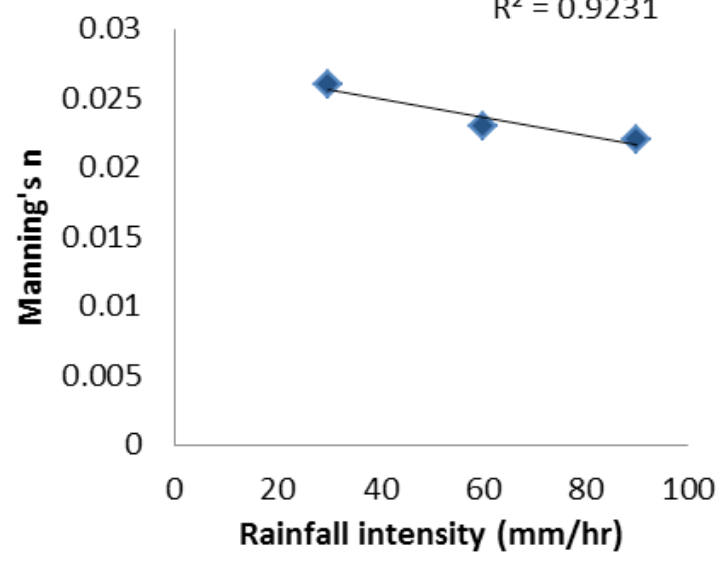

Figure 18. Variation of Manning's roughness with rainfall intensity for $2 \%$ slope of the plane. 
The comparison between the volume of observed and simulated hydrograph, its volumetric error, time to peak and Nash-Sutcliffe criterion for performance evaluation at different value of surface slope is shown in Table 1. The value of Manning's n obtained through calibration for different overland flow plane slope was plotted and given in Figure 14 It can be seen that from Figure 17 the value of $\mathrm{n}$ decreases linearly with increase in overland flow plane slope.

Further, the rainfall intensity is increased to $60 \mathrm{~mm} /$ $\mathrm{hr}$ and the value of slope of the overland plane is varied from $1 \%$ to $4 \%$ as shown in Figure 6 to 9 The comparison between the observed and computed volume, time to peak and the volumetric error and Nash-Sutcliffe efficiency shown in Table 2. The value of Manning's $n$ obtained through calibration for different overland flow plane slope was plotted and given in Figure 15 It can be seen that from Figure 18 the value of $n$ decreases linearly with increase in overland flow plane slope.

Now, the rainfall flow rate is increased to $90 \mathrm{~mm} / \mathrm{hr}$ and again slope of the overland plane is varied from $1 \%$ to $4 \%$. The observed overland flow hydrographs and simulated by the kinematic wave model is shown in Figure 10 to 13. A comparison between the observed and computed volume, time to peak and the volumetric error, and Nesh-Sutcliffe efficiency shown in Table 3. The value of Manning's n obtained through calibration for different overland flow plane slope was plotted and given in Figure 16 It can be seen that from Figure 19 the value of $\mathrm{n}$ decreases linearly with increase in overland flow plane slope.

From Figure 2 to 13 it can be seen that, after the start of the rainfall on the catchment, the water flow rate at the outlet increases raipdly with time, this portion of hydrograph is known as the rising limb. However at a certain time the water flow rate at the outlet equals the rainfall intensity, this time is known as time to peak. After the occurrence of time to peak the rainfall flow rate almost become constant with time. However the minor flactuation are still observed, these may be due to variety of reasons including actual flow phenamina. When the rainfall intensity is stopped the water flow rate at the catchment outlet start redusing at a very slow rate, this is known as the falling limb of the hydrograph. The results indicate a considerable difference between the observed and computed runoff volumes, time to peak, was obtained. Therefore, it can be inferred that the rainfall intensity and the surface slope are the major parameters controlling the characteristics of the outflow hydrograph.

It is observed from Table 1 to 3 that for a given rainfall intensity, an increases in the overland plane slope, reduces the time to peak. This may be due to raipd draing of the water due to increased surface slope. For a given rainfall intensity, the observed data were simulated very well at higher values of surface slope as compaired to lower value of surface slope. However we can also say that the at a given rainfallintensity the kinematic wave model give a better fit for a steeper value of surface slope. Simillarly, for a given surface slope, the observed data showed good agreement for higher values of rainfall intensity.

It was found that the nummerical model simulates the rising limb of the observed hydrograph very well, but the the falling limb of the hydrograph was underestimated. This may be due to fact that, when water moves on the surface in response to slope, it is postulated that two phenomena will act in conjuction to effectively alter the hydrodynamics of the soil water. Firstly, water moving on the soil surface will exert a small pull on pore water by applying an upward suction force that is proportional to $\mathrm{V}^{2} / 2 \mathrm{~g}$, where $\mathrm{V}$ is the average surface water velocity which is several orders of magnitude larger than the pore water velocity. Due to this suction force water from the pores are drained out and thus contirbute to the surface runoff which is not estimated by the one-dimentional kinematic wave model. Secondly, while applying the water on the catchment, after stoping the rainfallintensity, some amount of water is still stored in the overhead pipe. This volume of water is then released subsiquently from the nozzle due to the gravity. This amount of water, is not included in the numerical model.

\section{Conclusion}

The overland runoff hydrographs presented in this study was conducted in the laboratory with equipment consisting of a rainfall simulator (nozzle spray), an impermeable overland flow plane i.e. smooth metal sheet and a runoff recording system. The results indicate that there is less difference in the amount of runoff volumes, peaks at different rainfall intensities and slope of the catchments. But considerable difference in falling limb of hydrograph shapes. Future laboratory and field experiments will test relationships for a wider range of conditions that will include the use of other rainfall intensity, different slopes and infiltrating surfaces. Future work should also include 
the comparison of the experimental results with numerical results i.e. kinematic wave theory.

\section{Acknowledgements}

The laboratory experiments described herein were conducted in the Department of Hydrology, Indian Institute of Technology, Roorkee-247667 (India)

\section{List of notations}

$A=\operatorname{Area}\left(m^{2}\right)$

$C=$ Courent number

$D=$ Hydraulic depth $(m)$

$f=$ Infiltration rate $(\mathrm{mm} / \mathrm{hr})$

$g=$ Acceleration due to gravity $\left(\mathrm{m} / \mathrm{s}^{2}\right)$

$h=$ Depth of overland flow $(m)$

$i=$ Integer for space increment $(\mathrm{mm})$

$j=$ Integer for time increment $(s)$

$K=$ Hydraulic conductivity $(\mathrm{m} /$ day)

$k=$ Kinematic wave number

$L=$ Maximum length of flow $(m)$

$m=$ Kinematic wave parameter

NES = Nash-Sutcliffe Efficency (\%)

$n=$ Manning's roughness coefficient

$Q=$ Discharge in $\left(\mathrm{m}^{3} / \mathrm{s}\right)$

$q_{l}=$ Lateral inflow rate $(\mathrm{m} / \mathrm{s})$

$q_{0}=$ Overland flow $\left(\mathrm{m}^{3} / \mathrm{s}\right)$

$r=$ Rainfall intensity $(\mathrm{mm} / \mathrm{hr})$

$S=$ Slope of the catchment (\%)

$t=$ time increment $(s)$

$Y_{c}=$ Volume computed (\%)

$Y_{o}=$ Volume observed (\%)

$Y_{m}=$ Mean of observed value (\%)

$\Delta t=$ time step $(s)$

$\Delta x=$ Space step $(\mathrm{cm})$

$a=$ Kinematic wave parameter

$\alpha_{o}=$ kinematic wave parameter for overland flow

\section{References}

1. Bryan RB, Poesen J. Laboratory experiments on the influence of slope length of runoff, percolation and rill development. Earth Surface processes and Landforms. 1989; 14:211-31.

2. Chow VT, Maidment DR, Mays LW. Applied Hydrology. Singapore: McGraw-Hill, New York Book Co; 1988. p. 272309.
3. Ibanez CAS, Calvo A. Design and operation of a small and portable rainfall simulator for rugged terrain. Soil Technology. 1997; 11:163-70.

4. De Lima JLMP, Singh VP. The influence of the pattern of moving rainstorms on overland flow. Advances on Water Resources. 2002; 25(7):817-28.

5. De Lima JLMP, Singh VP. Laboratory experiments on the influence of storm movement on overland flow. Physics and Chemistry of the Earth. 2003; 28:277-82.

6. Henderson FM. Open Channel Flow. New York: The MacMillan Company; 1966.

7. Ajay G. Modeling of Rainfall Runoff process of a small catchment. [M.E dissertation (Hydrology)]. University of Roorkee, India; 1979.

8. Hossain MM. Application of kinematic wave theory to small watershed's. [Ph .D. Thesis]. University of Roorkee (India); 1989.

9. Das K, Ajit. Design and operation of a laboratory for rainfall runoff simulation. [M.E dissertation (Hydrology)]. University of Roorkee, India; 1983.

10. Lighthill MJ, Whitham GB. On kinematic waves. I. Flood movement in long rivers. Proc Royal Soc Lond. 1955; Series A 229(1178):281-316.

11. Nash JE, Sutcliffe JV. River flow forecasting through conceptual model. Part 1-A discussion of principles: Journal of Hydrology. 1970; 10:282-90.

12. Singh VP. Kinematic wave modeling in water resources. Surface-water hydrology, New York: Wiley; 1996.

13. Singh VP. A laboratory investigation of surface runoff. Journal of hydrology. 1975; 25(3-4): 187-200.

14. Smith RE, Woolhiser DA. Overland flow on infiltrating surface. Water Resources Research. 1971; 7(4):899-913.

15. Tekle, Alemayehu. The study of runoff mechanics of a natural watershed. [M.E dissertation (Hydrology)]. University of Roorkee, India; 1998.

16. Tossell RW, Dickinson WT, Rudra RP, Wall GJ. A portable rainfall simulation. Can Agric Eng. 1987; 29:155-62.

17. Turner AK. The simulation of rainfalls studies in overland flow. Journal Inst Eng Austr. 1965; 39:9-15.

18. Ponce VM. Engineering Hydrology: Principles and Practices. Englewood Cliffs, NJ: Prentice-Hall; 1989.

19. Ponce VM, Simons DB. Applicability of kinematic and diffusion models. J Hydr Div. ASCE. 1978; 104(3):353-60.

20. Willems P. A spatial rainfall generator for small spatial scales. Journal of Hydrology. 2001; 252:126-44.

21. Yen BC, Chow VT. A study of surface runoff due to moving rainstorms. Hydraulic Engineering Series No. 17, Department of Civil Engineering, University of Illinois, Urbana, USA. 1968. 